\title{
Comparison of Task Performance, Hand Power, and Dexterity with and without a Cock-up Splint
}

\author{
Moonyoung Chang ${ }^{1 *}$, NAm-Hae Jung ${ }^{2)}$ \\ 1) Department of Occupational Therapy, College of Biomedical Science and Engineering, \\ Inje University: 197 Inje Street, Gimhae, Gyeongsangnam-do 621-749, Republic of Korea \\ 2) Department of Rehabilitation Science, Graduate School, Inje University, Republic of Korea
}

\begin{abstract}
Purpose] The purpose of this study was to investigate the difference in task performance, grip and pinch strength, and dexterity with and without cock-up splints, which are widely used in occupational therapy practice. [Methods] Twenty-three participants performed Jebsen-Taylor hand function test and grooved pegboard for task performance and dexterity. The power grip and pinch strength was measured using Jamar hydraulic hand dynamometer and pinch gauge. [Results] In the result of the Jebsen-Taylor hand function test, task performance with the cock-up splint was slower compared to without the splint for all items. Men's grip power with the cock-up splint was found to be significantly decreased compared to without the splint. Women's grip and palmar pinch strength with the splint decreased significantly compared to without the splint. In the grooved pegboard test, the dexterity of both men and women with the cock-up splint decreased significantly compared to without the splint. [Conclusion] To assist patients to make wise decisions regarding the use of splints, occupational therapists must have empirical knowledge of the topic as well as an understanding of the theoretical, technical, and related research evidence. The results of this study will be useful in the analysis and understanding of changes in hand function in splint applications for people with hand dysfunction.
\end{abstract}

Key words: Dexterity, Hand power, Splint

(This article was submitted May 9, 2013, and was accepted Jun. 7, 2013)

\section{INTRODUCTION}

Splints can be categorized as static or dynamic splints. Such splints may serve a variety of purposes. Static splints are used for rest, prevention of further deformity, prevention of soft tissue contracture, and substitution for lost motor function. Dynamic splints are used for substitution of lost motor function, correction of a deformity, control of motion, and aid in fracture alignment and wound healing ${ }^{1}$.

Many studies have reported on the effects of splint applications for people with upper extremity dysfunction, such as decreasing hand and wrist pain ${ }^{2}$, improving hand function $^{3)}$, control of joint position and stability ${ }^{4}$, decreasing muscle tone ${ }^{5)}$, and improving muscle strength ${ }^{6}$.

Splints are used for a period of 1-24 months, and the average length of use has been reported to be 4 months ${ }^{7)}$. A splint application can lead to performance changes in activities of daily living (ADL). In rehabilitation, failure to adapt biopsychosocially can cause a decrease in voluntary participation. It is important to understand the changes that occur after splint application $^{8)}$.

*Corresponding author. Moonyoung Chang (e-mail: myot@ inje. ac.kr)

(C2013 The Society of Physical Therapy Science

This is an open-access article distributed under the terms of the Creative Commons Attribution Non-Commercial No Derivatives (by-ncnd) License $<$ http://creativecommons.org/licenses/by-nc-nd/3.0/> .
The purpose of this study was to determine the difference in hand function between participants who were and were not wearing a cock-up splint, which is widely used in occupational therapy practice. In particular, we investigated the differences in task performance, grip strength, and dexterity.

\section{SUBJECTS AND METHODS}

Twenty-three healthy individuals, who were " I " University students without musculoskeletal problems, were recruited for this study. The cock-up splints used in this study were created using low temperature thermoplastic material. They were customized to the forearms and hands of the participants and covered two-thirds the length of the forearm on the volar side. All participants read and signed an informed consent form, approved by Inje University Ethics Committee for Human Investigations prior to their participation.

Assessments of performance when participants were wearing or not wearing the splints were carried out in a random order. Task performance was assessed using the Jebsen-Taylor hand function test; power grip was measured using a Jamar hydraulic hand dynamometer (PC 5030JI, Preston Co., USA); and pinch grip (tip pinch, lateral pinch, palmar pinch) was measured using a Jamar hydraulic pinch gauge (PC 5030, Preston Co., USA). Dexterity was measured using a grooved pegboard. Data were analyzed using the SPSS 18.0 statistics package for Windows and a signifi- 
cance level of 0.05 was used in all analyses.

\section{RESULTS}

In this study, there were 7 men (30.4\%) and 16 women $(69.6 \%)$ in the sample. All participants were right handed. Subjects' average age was $22.35 \pm 2.17$ years old; their average height was $165.48 \pm 7.21 \mathrm{~cm}$; and their average weight was $56.70 \pm 9.75 \mathrm{~kg}$ (Table 1).

In the results of the Jebsen-Taylor hand function test, the scores obtained when wearing the cock-up splint were slower than without the splint for all items. The time spent in the writing item was $12.94 \pm 1.70$ seconds without the splint and $14.33 \pm 2.03$ seconds with the splint. In the turning cards item, the speed was $4.41 \pm 0.56$ seconds without the splint, and $5.31 \pm 1.21$ seconds with the splint. With and without the splints, the amounts of time spent on the small objects item were $7.47 \pm 1.91$ seconds and $5.71 \pm 0.65 \mathrm{sec}-$ onds, respectively. The feeding simulation item took $6.17 \pm$ 1.80 seconds without the splint and $7.36 \pm 1.72$ seconds with the splint, while the stacking checker item took $3.41 \pm 0.83$ seconds without and $4.77 \pm 1.55$ seconds with the splint. The amount of time spent on lifting large, light objects item was $2.49 \pm 0.28$ seconds without the splint and $3.31 \pm 0.82$ seconds with the splint. In lifting large, heavy objects item, it took $2.49 \pm 0.28$ seconds, to lift the item without the splint and $3.11 \pm 0.05$ seconds with the splint. All of these values showed a significant difference (Table 2).

Men's grip power wearing the cock-up splint was significantly lower compared to without the splint. The tip, lateral, and three pinch strengths when wearing the cock-up splint were lower compared to without the splint. However, no significant difference was observed. The grip power was $110.01 \pm 9.39 \mathrm{~kg}$ without the splint and $82.12 \pm 24.55 \mathrm{~kg}$ with the splint. Tip pinching was $16.01 \pm 2.50$ without the splint and $15.65 \pm 2.43 \mathrm{~kg}$ with the splint. Lateral pinching was $26.13 \pm 3.14 \mathrm{~kg}$ without the splint and $24.42 \pm$ $2.77 \mathrm{~kg}$ with the splint, while three jaw pinching was 24.53 $\pm 4.59 \mathrm{~kg}$ without the splint and $22.62 \pm 3.62 \mathrm{~kg}$ with the splint. Women's grip power and three jaw pinching with the splint were significantly lower compared to without the splint; the powers of tip and lateral pinching with the splint were not significantly lower than without the splint. The grip power was $61.60 \pm 11.84 \mathrm{~kg}$ without the splint and $44.32 \pm 10.25 \mathrm{~kg}$ with the splint. Tip pinching was 11.29 $\pm 2.01 \mathrm{~kg}$ without the splint and $10.88 \pm 1.78 \mathrm{~kg}$ with the splint. Lateral pinching was $16.69 \pm 1.42 \mathrm{~kg}$ without the splint and $16.27 \pm 2.03 \mathrm{~kg}$ with the splint, while three jaw pinching was $15.40 \pm 2.11 \mathrm{~kg}$ without the splint and $14.12 \pm$ $2.16 \mathrm{~kg}$ with the splint (Table 3).
In the grooved pegboard test, men took $55.73 \pm 4.86 \mathrm{sec}-$ onds without the splint and $70.14 \pm 5.96$ seconds with the splint. Women took $53.46 \pm 4.40$ seconds without the splint and $69.65 \pm 11.21$ seconds with the splint. Both differences

Table 1. Characteristics of subjects $(n=23)$

\begin{tabular}{lcc}
\hline \multicolumn{2}{c}{ Characteristics } \\
\hline \multirow{2}{*}{ Gender } & Male & $7(30.4)^{*}$ \\
& Female & $16(69.6)^{*}$ \\
\multirow{2}{*}{ Handedness $\quad$ Left } & $0(0.0)^{*}$ \\
& Right & $23(100)^{*}$ \\
Age (years old) & $22.4 \pm 2.2^{* *}$ \\
Height $(\mathrm{cm})$ & $165.5 \pm 7.2^{* *}$ \\
Weight $(\mathrm{kg})$ & $56.7 \pm 9.8^{* *}$ \\
\hline$* 20$
\end{tabular}

Table 2. The results of the Jebsen-Taylor hand function test (Unit: seconds)

\begin{tabular}{lcc}
\hline Items & $\begin{array}{c}\text { Without splint } \\
(\text { mean } \pm \text { SD) }\end{array}$ & $\begin{array}{c}\text { With splint } \\
(\text { mean } \pm \text { SD) }\end{array}$ \\
\hline Writing* & $12.9 \pm 1.7$ & $14.3 \pm 2.0$ \\
Card turning* & $4.4 \pm 0.6$ & $5.3 \pm 1.2$ \\
Small objects* & $5.7 \pm 0.7$ & $7.5 \pm 1.9$ \\
Feeding simulation** & $6.2 \pm 1.8$ & $7.4 \pm 1.7$ \\
Stacking checkers* & $3.4 \pm 0.8$ & $4.8 \pm 1.6$ \\
Lifting large, light objects* & $2.5 \pm 0.3$ & $3.3 \pm 0.8$ \\
Lifting large, heavy objects* & $2.5 \pm 0.3$ & $3.1 \pm 0.1$ \\
\hline
\end{tabular}

$* \mathrm{p}<0.05, * * \mathrm{p}<0.01$

Table 3. Comparison of handpower with and without a splint (Unit: $\mathrm{kg}$ )

\begin{tabular}{|c|c|c|c|c|}
\hline & & & Without splint & With splint \\
\hline \multirow{4}{*}{ Men } & \multicolumn{2}{|c|}{ Power grip* } & $110.0 \pm 9.4$ & $82.1 \pm 24.6$ \\
\hline & & Tip & $16.0 \pm 2.5$ & $15.7 \pm 2.4$ \\
\hline & \multirow[t]{2}{*}{ Pinch } & Lateral & $26.1 \pm 3.1$ & $24.4 \pm 2.8$ \\
\hline & & Three jaw & $24.5 \pm 4.6$ & $22.6 \pm 3.6$ \\
\hline \multirow{4}{*}{ Women } & \multicolumn{2}{|c|}{ Power grip** } & $61.6 \pm 11.8$ & $44.3 \pm 10.3$ \\
\hline & \multirow{3}{*}{ Pinch } & Tip & $11.3 \pm 2.0$ & $10.9 \pm 1.8$ \\
\hline & & Lateral & $16.7 \pm 1.4$ & $16.3 \pm 2.0$ \\
\hline & & Three jaw* & $15.4 \pm 2.1$ & $14.4 \pm 2.2$ \\
\hline
\end{tabular}

$* \mathrm{p}<0.05, * * \mathrm{p}<0.01$

Table 4. Comparison of grooved pegboard test results with and without the cock-up splint (Unit: seconds)

\begin{tabular}{lrccc}
\hline & \multicolumn{2}{c}{ Men* } & \multicolumn{2}{c}{ Women* } \\
\cline { 2 - 5 } & Without & With & Without & With \\
\hline Grooved pegboard test & $55.7 \pm 4.9$ & $70.1 \pm 6.0$ & $53.5 \pm 4.4$ & $69.7 \pm 11.2$ \\
\hline$* \mathrm{p}<0.05$ & & & &
\end{tabular}


were significant (Table 4).

\section{DISCUSSION}

The aim of this study was to investigate the effect of wearing a cock-up splint on task performance, grip and pinch strength, and dexterity. The Jebsen-Taylor hand function test was designed to provide a short, objective test of hand functions commonly used in ADL, and this was used to measure task performance in this study. For all items, performance was delayed when wearing the cock-up splint compared to not wearing the splint; the time difference with and without the splint was 2 seconds or less. This accords with Carlson and Trombly's results ${ }^{9}$; they emphasized that a time delay of 2 seconds or less can lead to a severe handicap in ADL.

Grip strength, three jaw pinch strength, and dexterity of women when wearing the cock-up splint showed a significant decrease compared to not wearing the splint. This was different from the results of Burtner et al. ${ }^{10)}$ and Burtner et $\mathrm{al}^{11)}$. Although it is impossible to definitively explain the contradiction of these results, there are two plausible explanations. The participants in the two previous studies had rheumatoid arthritis (RA) and cerebral palsy (CP), respectively. In contrast to the participants of this study, they had limited range of motion, pain, weakness, and other symptoms. This may have affected grip, pinch strength, and dexterity when not wearing the splint. Also, a cock-up splint might have supported the wrist of subjects with RA or CP, and reduced pain when wearing the splint. Three jaw pinching requires the use of most of the fingers. Thus, we consider this is the reason why only three jaw pinch strength showed a significant difference. Although grip strength, three-jaw pinch strength, and dexterity of women when wearing the cock-up splint exhibited significant decreases compared to not wearing the splint, the data were within the normal range reported by Park et al. ${ }^{12)}$ and Trites ${ }^{13)}$.

In their study, Agnew and Mass ${ }^{14)}$ reported that only $15.6 \%$ patients who were prescribed the splint were fully compliant due to the mildness of symptoms, poor cosmesis, discomfort, dysfunction in ADL, failure to relieve pain, and other causes ${ }^{15,16)}$. Splint intervention should be customized by, taking the individual's unique biological or physical and psychosocial needs into consideration, along with personal factors and the patient's specific context, including life roles and environment ${ }^{8}$. Failure to use a holistic approach for splint application may result in patients experiencing unexpected challenges which cause them to stop wearing the splint. It is also the role of occupational therapists to teach patients about changes that could occur after splint application and suggest ways of coping with them.
To assist patients to make wise decisions regarding the use of splints, occupational therapists must have empirical knowledge, as well as an understanding of the theoretical and technical aspects and related research evidence ${ }^{17)}$. Although the participants of this study were healthy persons, it would be useful to analyze and understand the changes of hand function in splint applications for people with hand dysfunction. Studies comparing hand functions of people with various musculoskeletal disorders with and without a splint will be needed in the future.

\section{REFERENCES}

1) Coppard BM, Lohman H: Introduction to Splinting: A clinical reasoning and problem-solving approach, 3rd ed. St. Louis: Mosby Elsevier, 2008.

2) Henderson SE, McMillan IR: Pain and function: occupational therapist's use of orthotics in rheumatoid arthritis. Br J Occup Ther, 2002, 65: 165171

3) Imms C, Meester-Delver A, Folmer K, et al.: Bracing and splinting interventions in the upper limbs of people with cerebral palsy. Dev Med Child Neurol, 2011, 53: 293-294. [Medline] [CrossRef]

4) Weiss AP, Moore DC, Infantolino C, et al.: Metacarpophalangeal joint mechanics after 3 different silicone arthroplasties. J Hand Surg Am, 2004, 29: 796-803. [Medline] [CrossRef]

5) Wilton J: Casting, splinting, and physical and occupational therapy of hand deformity and dysfunction in cerebral palsy. Hand Clin, 2003, 19: 573-584. [Medline] [CrossRef]

6) Vaz DV, Mancini MC, Fonseca ST, et al.: Muscle stiffness and strength and their relation to hand function in children with hemiplegic cerebral palsy. Dev Med Child Neurol, 2006, 48: 728-733. [Medline] [CrossRef]

7) Brininger TL, Rogers JC, Baker NA, et al.: Efficacy of a fabricated customized splint and tendon and nerve gliding exercised for the treatment of carpal tunnel syndrome: a randomized controlled trial. Arch Phys Med Rehabil, 2007, 88: 1429-1435. [Medline] [CrossRef]

8) McKee PR, Rivard A: Biopsychosocial approach to orthotic intervention. J Hand Ther, 2011, 24: 155-162. [Medline] [CrossRef]

9) Carlson JD, Trombly CA: The effect of wrist immobilization on performance of the Jebsen Hand Function Test. Am J Occup Ther, 1983, 37: 167-175. [Medline] [CrossRef]

10) Burtner PA, Anderson JB, Marcum ML, et al.: A comparison of static and dynamic wrist splints using electromyography in individuals with rheumatoid arthritis. J Hand Ther, 2003, 16: 320-325. [Medline] [CrossRef]

11) Burtner PA, Poole JL, Torres T, et al.: Effect of wrist hand splints on grip, pinch, manual dexterity and muscle activation in children with spastic hemiplegia: a preliminary study. J Hand Ther, 2008, 21: 36-42. [Medline] [CrossRef]

12) Park CY, Yim HW, Koo JW, et al.: Normative data of grip and pinch strength for screening of cumulative trauma disorders. Korean J Occup Environ Med, 1998, 10: 362-367.

13) Trites R: Grooved pegboard test user instruction. Lafayette Instrument, 2002, www.lafayetteinstrum ent.com. (Accessed MM. DD, 20YY).

14) Agnew P, Maas F: Compliance in wearing wrist working splints in rheumatoid arthritis. Occup Ther J Res, 1995, 15: 165-180.

15) Groth GN, Wulf MB: Compliance with hand rehabilitation: health beliefs and strategies. J Hand Ther, 1995, 8: 18-22. [Medline] [CrossRef]

16) Spoorenberg A, Boers M, Van der Linden S: Wrist splints in rheumatoid arthritis: what do we know about efficacy and compliance. Arthritis Care Res, 1994, 7: 55-57. [Medline] [CrossRef]

17) Egan MY, Brousseau L: Splinting for osteoarthritis of the carpometacarpal joint: a review of the evidence. Am J Occup Ther, 2007, 61: 70-78. [Medline] [CrossRef] 